\title{
PLASTIC SPLINTS AND APPLIANCES IN ORTHOPAEDIC SURGERY
}

\author{
Woolf Herschell and John T. Scales, London, England
}

From the Institute of Orthopaedics, Royal National Orthopaedic Hospital. Stanmore, Middlesex

A wide range of plastic materials is now available in industry. It was thought that a number of these might be suitable for the construction of orthopaedic splints and they have been tried with varying degrees of success. Most have been found unsuitable for one reason or another, some because the technique of manipulation was too elaborate, and others because they were lacking in certain necessary qualities. The practical properties required of plastic materials for use in splint-making include: relative ease of manipulation; durability; resistance to fatigue strain; light weight; radiolucency and transparency; inertness to chemical agents; freedom from irritants causing dermatitis; porosity; cheapness. No plastic material satisfies all these requirements but several are available which satisfy most of them. The ideal plastic will be one which after direct application to the patient, or to a mould, will polymerise rapidly to form a rigid material (cf. gypsum) or alternatively one which is soluble in high concentration, about 80 per cent., in a cheap solvent such as water. The curing or setting time must not exceed fifteen to twenty minutes and should preferably be less. Such a plastic when cured or set should have the properties enumerated above. We hope that this goal may be achieved by experimental work now proceeding.

Plastic materials may be divided into two main groups: 1) thermoplastic resins which can be resoftened and remoulded by the application of heat and pressure; 2 ) thermosetting resins which become more or less permanently hard and insoluble on curing (Worner 1946) ${ }^{1}$. The materials which have been considered experimentally for the construction of splints include: Thermoplastic-methyl methacrylate, polyvinyl chloride (P.V.C.), polyvinyl acetate (P.V.A.), P.V.C. \& A. copolymer, cellulose acetate, polythene, polystyrene; Thermosetting - high pressure-phenolformaldehyde, casein formaldehyde, urea formaldehyde; Thermosetting - low pressurc-allyl and polyester resins.

It was hoped that new low-pressure thermosetting resins would eliminate some of the difficulties in processing which are found with high-pressure resins, and at the same time have the additional property of high tensile strength which non-laminated thermoplastic materials lack. To date, however, these materials have been found unsuitable for individual splint-making although experimental work in artificial limb production shows promise of success. Of thermoplastic materials, those nearest to our requirements have so far been methyl methacrylate, P.V.C. and P.V.C. \& A. copolymer-each having their usefulness in different types of splints.

It should be noted that if great strength is required a laminated plastic is essential. Laminating materials which can be used include glass fibre cloth, cotton, paper, and asbestos. Such lamination does, however, require modification of the usual technique.

External splints using woven cellulose acetate and glass fibre in bandage form have been described (Anderson and Erickson 1945) ${ }^{2}$. The plastic bandage is wetted with a setting solution and applied directly to the patient. A trial of these bandages shows that they have many advantages as compared with plaster-of-Paris bandages, but certain disadvantages have still to be overcome. Their merits include: lightness of weight-not more than onequarter to one-sixth the weight of plaster of Paris; strength and durability when in complete cast form; coolness in wearing; admission of light and air; capability of sterilisation by autoclaving; the fact that they are waterproof, porous, and unaffected by body secretions; and the ease and cleanliness of application. Nevertheless there are disadvantages. 1) The process involves evaporation of acetone which is an expensive and inflammable solvent.

$$
{ }^{1} \text { Australian Plastics, 1, } 26 . \quad 2 \text { American Journal of Surgery, 69, } 299 .
$$


Great care must be taken that a dangerous concentration of acetone vapour does not accumulate. A case of acute acetone poisoning after the application of casts made of synthetic plaster substitutes in which the solvent-evaporating agent was acetone, and in which the route of absorption was by the lungs, has been reported by Chatterton and Elliott $(1946)^{3}$. 2) Slow setting-As in all evaporating processes a "skin " is formed on both surfaces of the setting splint through which the residual solvent, trapped within, must diffuse before the splint can harden completely. 3) Sharp edges and rough surfaces are left when the cast has dried. 4) Hand-moulding to produce accurate fitting as in the technique of application of plaster of Paris is difficult. The use of crêpe bandage which has been suggested does not give sufficiently accurate moulding.

Acrylic splints have been recommended by Campbell $(1944)^{4}$, McGowan $(1943,1945)^{5,6}$, and Cholmeley (1945) ${ }^{7}$. The obvious advantages are elegance of appearance, low specific gravity, cleanliness in use and radiolucency. Blaine $(1945,1946)^{8,9}$ holds that these merits are offset by too many drawbacks, but we do not share this opinion. We agree that indirect application by the dental technique is complicated, but there is no need to use such a method. We disagree that " the plastic splint allows sweat to accumulate; pruritis develops and the skin becomes smelly." Ventilation of the splint, as described later, presents no difficulty. Moreover plastic splints do not differ in this respect from plaster-of-Paris splints which are worn continuously for any length of time.

\section{SPECIAL TYPES OF SPLINTS}

It might appear that hand manipulation of thermoplastics should be simple, for the reason that the materials become limp and " rubbery" when they are heated. Unfortunately this is far from true. The limp, heat-softened plastic alters shape readily in one or even two planes, but to mould it accurately against a plaster cast of a limb, and to hold it everywhere in apposition while cooling, requires considerable pressure and much skill. It is true that the construction of smaller splints presents relatively little difficulty but for large and complex splints, special technique and apparatus are essential.

Plaster-of-Paris casts are generally used in the manufacture of plastic splints because the temperature to which the plastic must be heated in order to allow successful manipulation is too high for direct moulding to the skin. Attempts to lower the softening point of thermoplastics, so that they can be hand-moulded to the body without burning the skin, can result only in a material which deforms under average living conditions such as sitting in front of a fire or in the sun. So far as practicable only negative plaster casts, easily taken by anyone conversant with plaster technique, were used in the production of these plastic splints. This technique is universally used and known. In the making of plastic splints care should be taken, especially where deep curves of small radius are present, to make the plaster cast several inches longer than the splint which is to be designed. Re-entrant curves at the edges of the cast must be avoided. Moreover it is desirable to grease the inside of the cast, or at least its edges and deep folds, with a lubricant such as petroleum jelly in order to allow the sheet plastic to flow easily while being moulded.

Of the two main groups of splints listed below, the smaller type can be made in any hospital with small workshop facilities. The larger type requires experienced technique and elaborate apparatus, but a supply would be practicable under a regional scheme of orthopaedic appliance manufacture without too great a cost of production. Group 1-Small splints : 1) limb gutters, 2) angled splints (elbow, knee, ankle), 3) cock-up splints, 4) opponens splints, 5) insoles. Group 2-Large splints: 1) anterior and posterior shells, 2) spinal jacket, 3) Minerva jacket and cervical support, 4) hip spica, 5) bucket and pylon, 6) plastic liner.

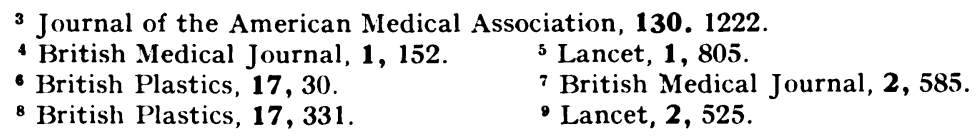

Vol. $30 \mathrm{~B}$, No. 2, MAY 1948 


\section{GROUP 1-SMALL SPLINTS}

For orthopaedic work, which generally entails the making of individual splints for individual patients, the use of standard shaped plastic splints is inadequate, even though it is claimed that minor local adjustments can be made by simple heating. Anyone who

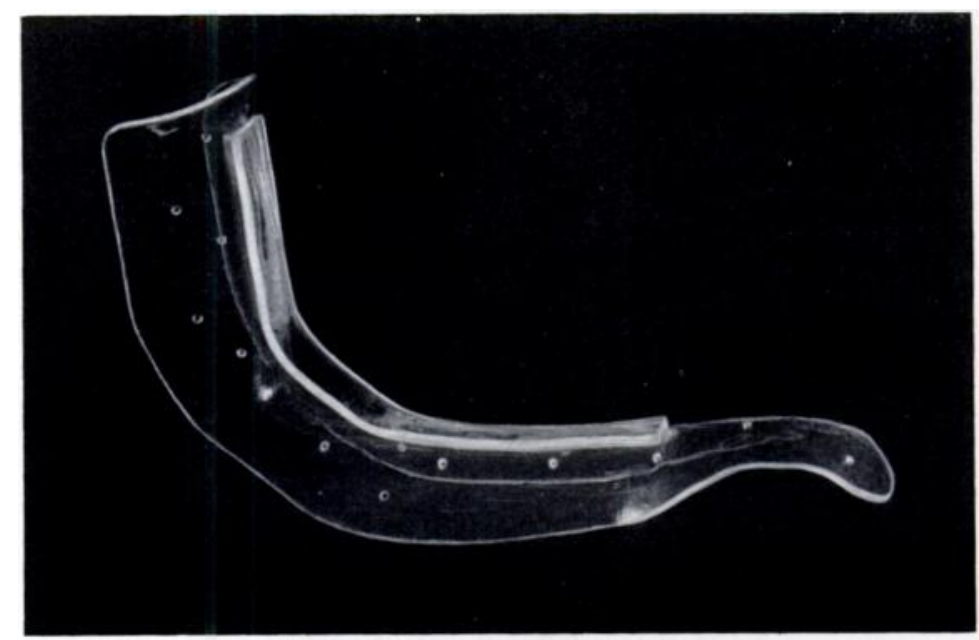

FIG. 1

Angled anterior elbow splint with reinforcing bar.

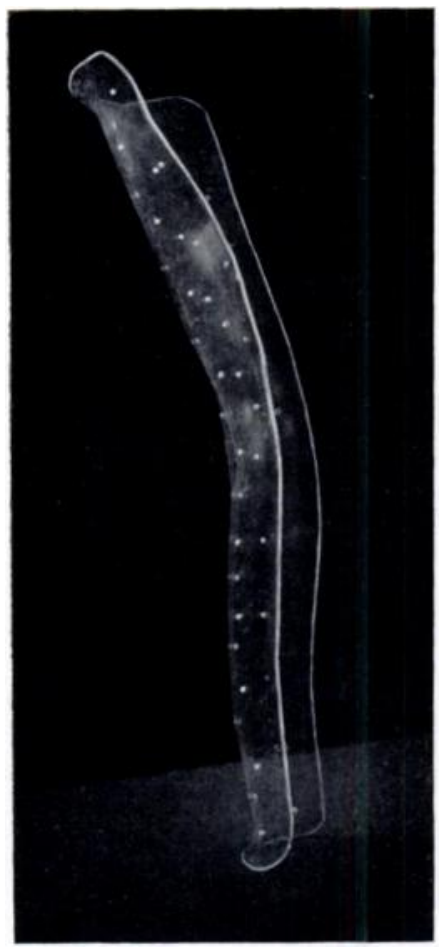

IFIG. 2

Knee gutter splint.

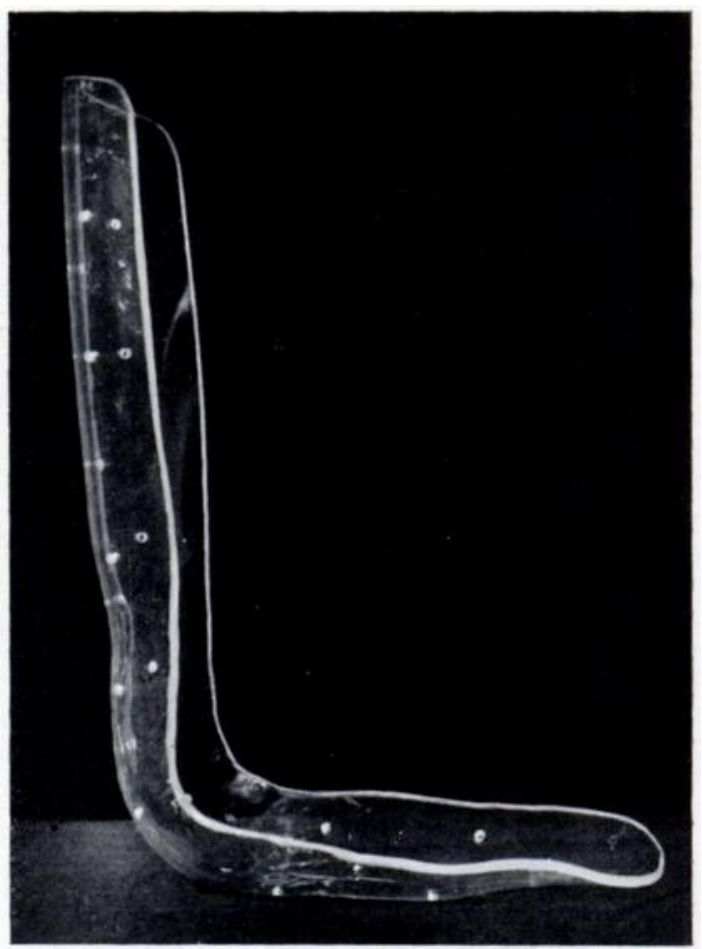

Fig. 3

Ankle splint.

can mould a standard splint accurately to fit an individual patient, can more cheaply make a much better splint tailored to the limb, starting with a negative plaster cast and a length of sheet plastic. 
1. Upper and lower limb gutters (one operator, Fig. 2) - These splints are made by handpressing heated pieces of plastic sheet of appropriate size and thickness into negative plaster casts (Scales and Herschell 1945) ${ }^{\mathbf{1 0}}$. Such splints can also be made on positive plaster casts. As gutter splints obtained from direct moulding in a negative cast are adequate, it is unnecessary to increase cost and time of production by making positive plaster casts from the negative before processing. When enveloping splints are required, positive casts may be needed.

2a. Angled splints (two operators, Fig. l)-Anterior elbow and posterior knee splints have been formed entirely by hand from sheet plastic of appropriate thickness (oneeighth or three thirty-seconds inch) cut to the approximate surface area required before

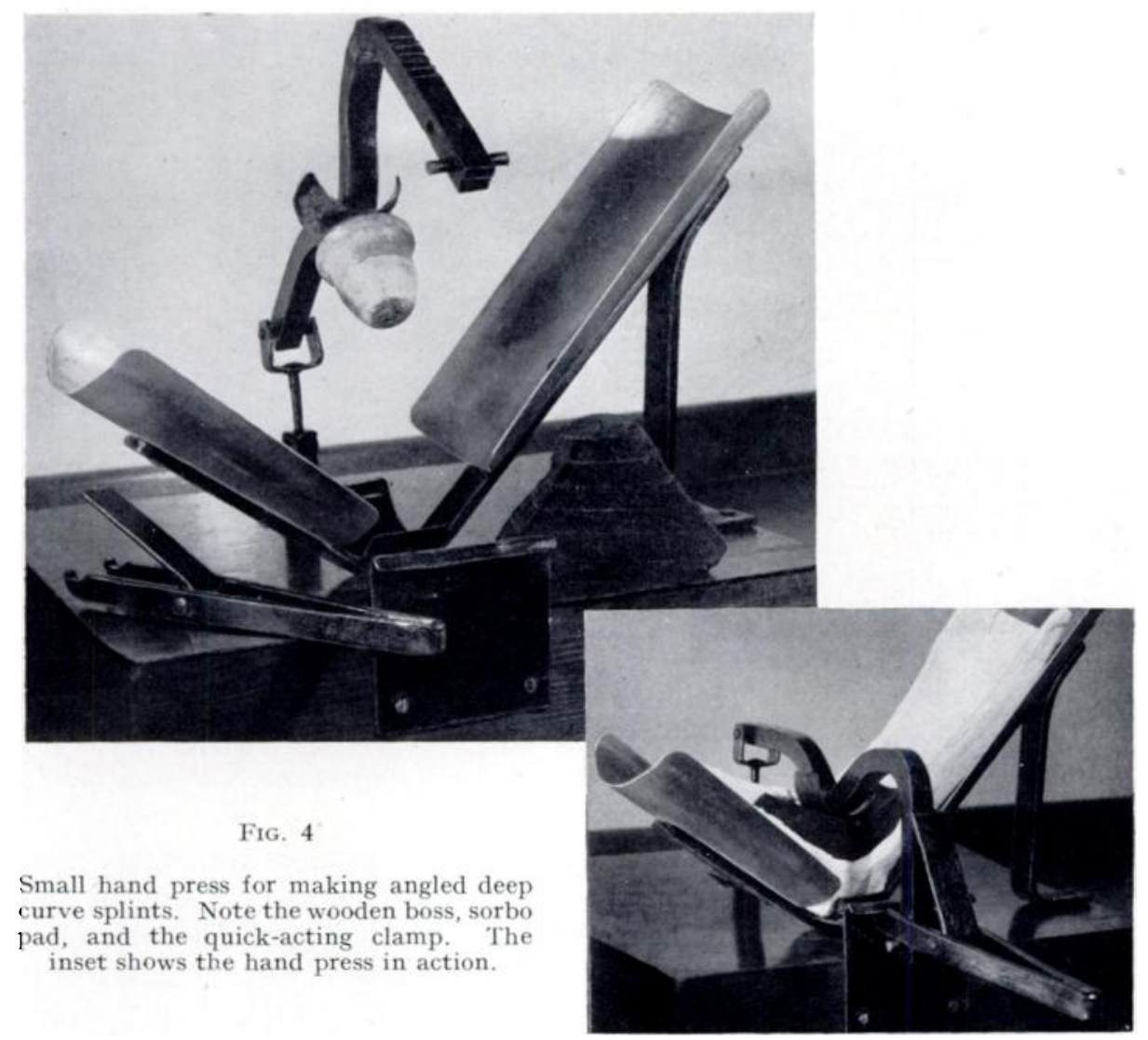

processing. It is important that the width of the strip should not exceed the segmental circumference of the cast at any level because excess material makes accurate hand-moulding extremely difficult. The strip of material is heat-softened and laid in the negative cast by the first operator, who holds it firmly in one half of the splint. The second operator then drags the remainder of the strip over the angle into the other half of the splint, holding it there and moulding it against the inside of the plaster cast until the material has hardened. Since there is considerable leverage on these splints it is advisable to cement a plastic strut across the angle.

2b. Angled splints (one operator) - Posterior elbow and ankle splints (Fig. 3) could not be made in this way because it was found impossible to secure sufficient pressure by hand to

${ }^{10}$ Scales, J. T., and Herschell, W. (1945) : British Medical Journal, 2, 423. 
reach the depth required for the heel or the point of the elbow where there are deep narrow curves in two planes. A simple hand press was devised by our technical assistant to overcome this difficulty (Fig. 4). It consists essentially of a right-angled metal rest to carry the plaster cast, bolted to a bench; and a quick-action clamp carrying a boss which is so fitted to the bench that, when it is brought over and locked, it presses a sorbo pad into the heel. The heat-softened tailored plastic strip is laid in the cast, the clamp brought over the heel portion and locked, thus forcing and maintaining the plastic to the full depth of the cast at the heel or olecranon. The foot and calf portion of the splint can then be moulded by hand. Using this simple apparatus the whole operation can be done in a few minutes by one technician.

3. Cock-up splint (one operator, Figs. 6, 7, and 8)-These are made by hand-pressing strips of plastic, which have been cut to approximate size, into a negative plaster cast. When cool, the moulded plastic is trimmed of excess material, and the edge of the palm area is everted to obtain a boss-like effect by careful local heating and finger manipulation.

4. Opponens splint (one operator, Fig. 9)-This splint, originally described by Cholmeley $(1945)^{7}$, has been improved and is in common use at the Royal National Orthopaedic Hospital, Stanmore. So far, the best available materials have been found to be P.V.C. \& A. copolymer, and methyl methacrylate, the former giving a better "spring" effect. It is made to fit the patient's hand, using only a paper templet. Fig. 10 shows a strip of copolymer, cut to pattern, and the finished splint. The templet can easily be varied in size to fit individual hands. Technique: The tailored strip of plastic is carefully softened by heating over a diffused Bunsen flame, and the major curve is set freehand where it is judged that it will turn round the second metacarpal, will allow the tongue to lie in the first interosseous space, and will hold the thumb in the opposed position. The two secondary curves are then formed so as to turn round the estimated positions of the thenar and hypothenar eminences respectively, using careful local heating at the appropriate areas with a very small Bunsen jet flame. The tongue is next locally heated and turned over into the splint, and at the same time the edges of the tongue are fashioned to form two flanges. This flanged tongue will fit over the first web, holding the heads of the first and second metacarpals apart without causing harmful skin pressure. Note: All heating of the splint is carried out away from the patient and the splint is applied only when cool. With practice, the number of fittings required during the making of it are few. This splint is the cheapest, easiest made, and most effective type yet evolved for opponens paralysis.

5. Insoles (one operator, Fig. 5) - Valgus insoles with or without metatarsal pads have been made experimentally by our technical assistant, using methyl methacrylate, "hard " P.V.C., and P.V.C. \& A. copolymer. The method employed is to press a heat-softened piece of sheet plastic material of the necessary shape and thickness on to a wood last corresponding to the patient's foot size, using a simple hand-press apparatus. The insoles are then trimmed and drilled for ventilation. They have been found very comfortable in use but fatigue strain has occurred in the material, a fault which can probably be eliminated from sheet plastic in the future.

Fixation of small splints-Where a splint has to be held to a limb the methods of fixation include: 1) overall crêpe bandaging; 2) adhesive strapping; 3) slot and strap (Fig. 7); slots are cut near the margin of the splint on both sides at appropriate levels and buckle straps threaded through; 4) stud and strap; shaped studs made from scrap material (Fig. 6a) are pressed into drill-holes in the long axis of the splint, the bases of the studs having been previously heat-softened; when cool these are held securely fixed; encircling soft straps are then fitted, one stud being sufficient for each strap; 5) combined slot, stud, and strap (Figs. 6 and 8). Straps may be either leather or plastic.

' Cholmeley, J. A. (1945): British Medical Journal, 2, 585. 


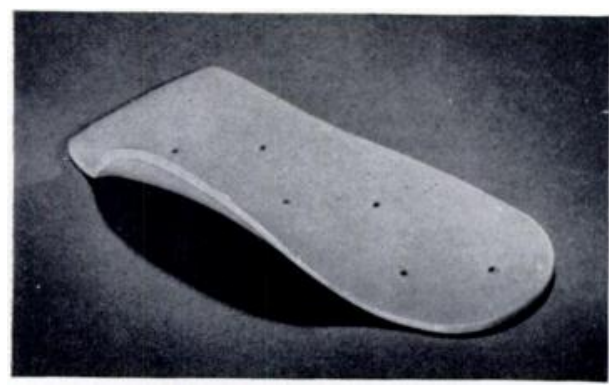

FIG. 5

Insole made of " hard " P.V.C"

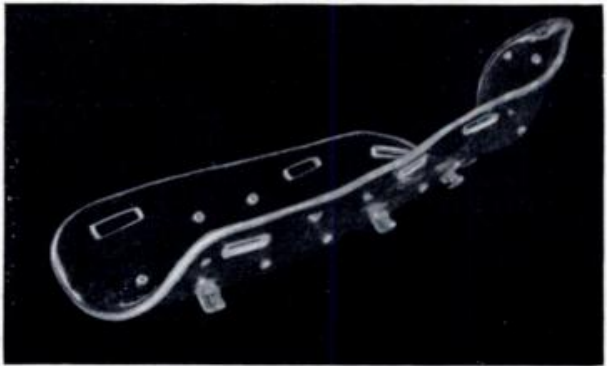

Fig. 6

Cock-up splint with slots and studs.

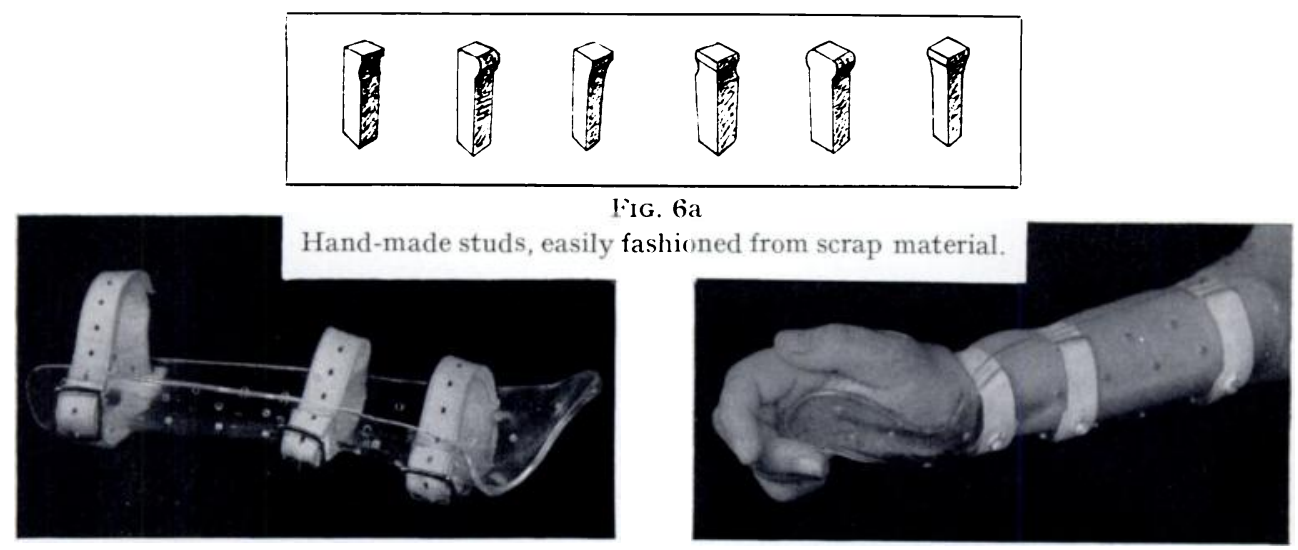

Fig, 7

Cock-up splint with slot and strap fixation.

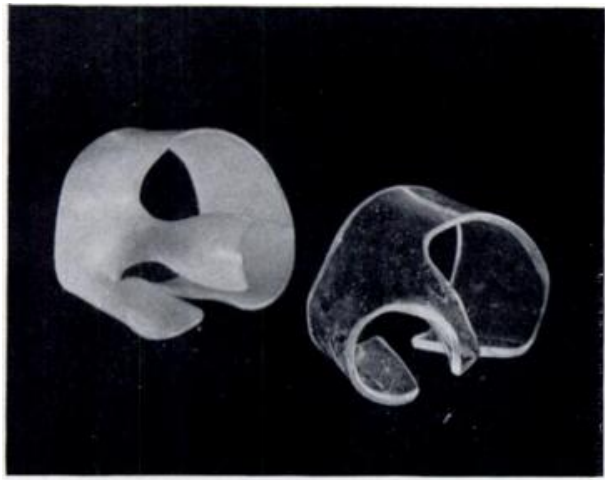

FIG. 9
FIG. \&

Slot, stud, and strap fixation.

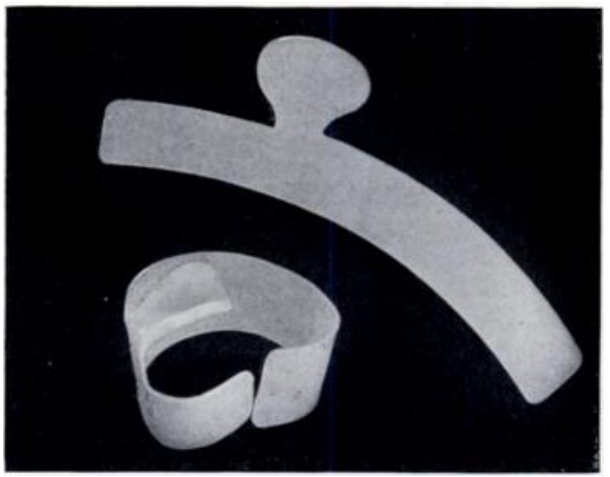

I.IG. 10

Opponens splints. In Fig. 9 the left splint is made of copolymer and the right of methacrylate. Fig. 10 shows a strip of copolymer cut to shape. Note the set of the curves in the finished splint.

Ventilation of splints (small and large)-As already noted, porosity is desirable. Where such plastics as are being used lack this characteristic, ventilation is ensured by multiple small drill-holes of approximately one-eighth inch diameter.

vol. $30 \mathrm{~B}$, No. 2 , MAY 1948 


\section{GROUP 2-LARGE SPLINTS}

This group requires two operators, a specially equipped workshop, technical skill, and experience of plastics. The splints have been made with thermoplastic material using negative plaster casts and pressure blowing. When made for special cases in which ordinary splinting was inadequate the results have been most gratifying. The stage has not yet been reached,

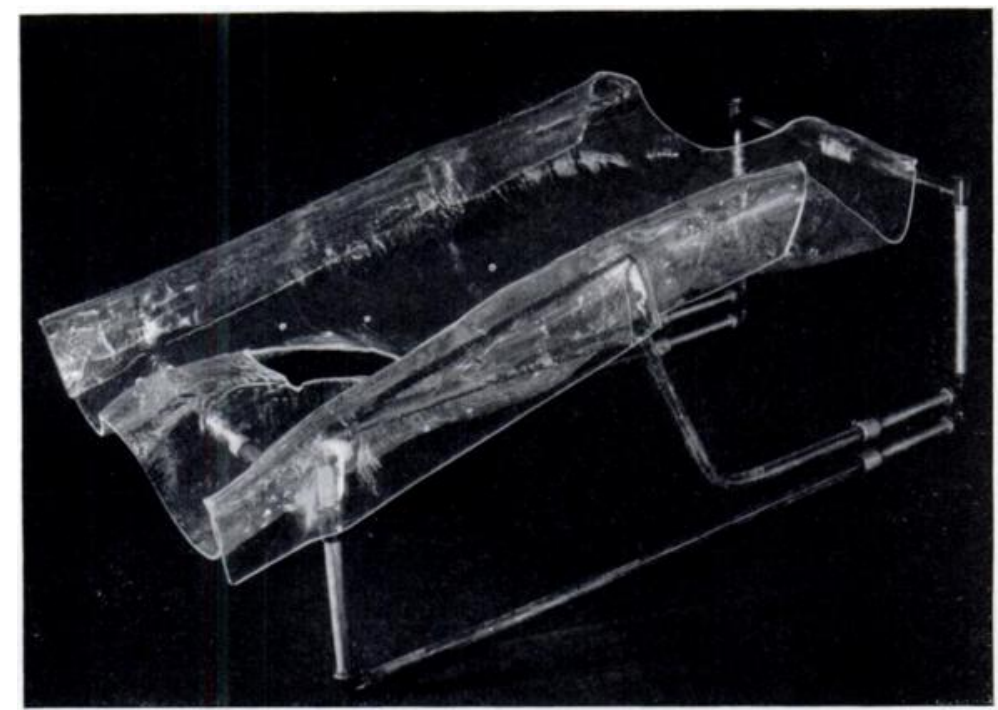

IFIG. 11

l'ssterior shell mounted on a standard adjustable frame.

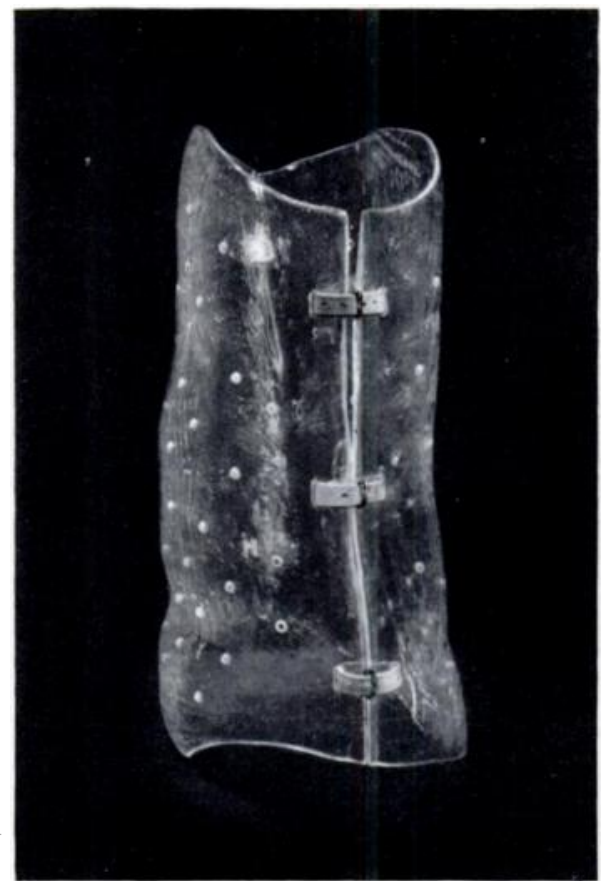

Fig. 12

Spinal jacket.

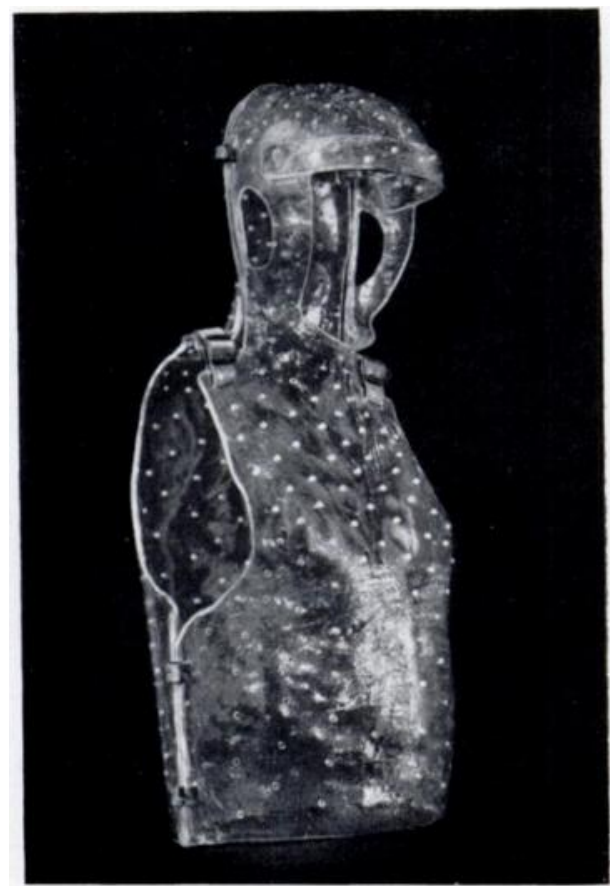

FIG. 13

Minerva jacket.

THE JOURNAL OF BONE AND JOINT SURGERY 
however, where the routine use of such splints is practicable, owing to the present relatively high cost of plastic material. Experimental work with plastic laminates using negative or positive plaster casts are promising, and it may be that these can be developed sufficiently. for routine use.

When plaster casts are used as negative moulds a modification is necessary to make them suitable for use in the pressure-blowing apparatus. This is a flange which is added by laving plaster slabs across the cast, allowing them to project two or three inches (Fig. 18). In the case of anterior and posterior shells the flanges are formed automatically while the cast is being made.

1. Anterior and posterior shells (Fig. 11)The method of production of these large body shells has been described previously (Scales and Herschell 1945). It consists essentially in the use of a pressure-blowing apparatus in which a heat-softened sheet of plastic can be blown by compressed air into a negative plaster cast. The plastic mould is then cut out, drilled for rentilation, and mounted on a standard adjustable fram . If required, slots and soft straps can be used for strict immobilisation of the trunk and thighs.

2. Spinal jacket (Fig. 1:2) -A plaster cast of the trunk is made in the usual manner, and bi-ralved along the mid-axillary lines. The two halves are joined end-to-end and the whole is flanged with plaster slabs. When dry, this negative cast is placed in the pressure-blowing apparatus and a softened sheet of plastic material is blown to the shape of the negative mould. After cutting out, two plastic halfjackets are obtained which are finally trimmed, drilled, and fitted. The slot and strap method is used for fixation. The most suitable material for jackets so far used is methyl methacrylate, but it is probable that thermoplastic laminates will supersede it. Inlike celluloid jackets, as made at present with reinforcing duralumin strips, methyl methacrylate jackets need no reinforcement.

A laminate type of jacket has been described by Collinson $(1946)^{11}$. There are, however, certain difficulties in its production which we

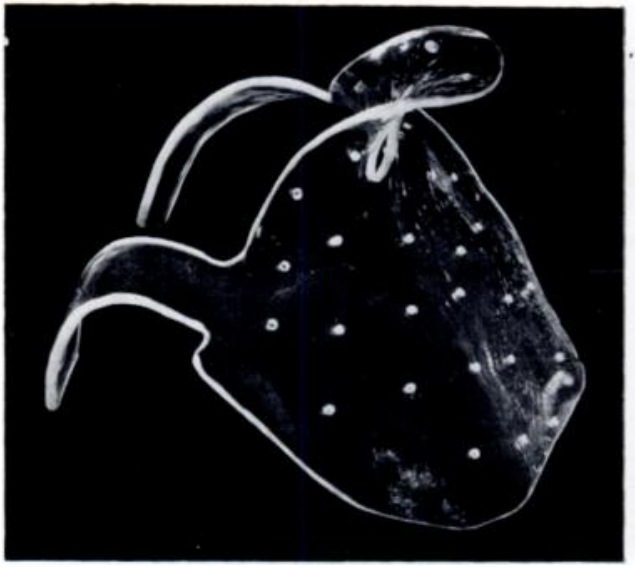

Fig. 14

(ervical support with breast plate, chin support, and shoulder straps-one-piece moulding. No additional fixation is required.

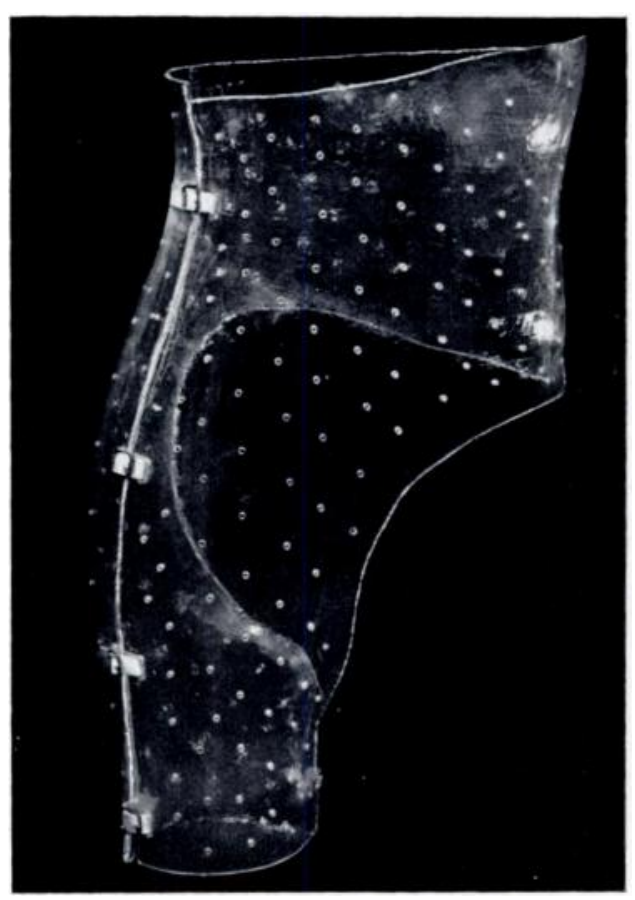

Fig. 15

Hip spica. also have found in experimental work with laminates. The main disadrantage of thermosetting resins such as used by Collinson (1945) is their tendency to cause dermatitis. 3. Minerva jacket and cervical support-These splints were ued for special cases where immobilisation of the cervical spine was required. The Minerva jacket (Fig. 13) has

$$
11 \text { Collinson, H. A. (1946): Lancet, 2, } 215 .
$$

VOL. $30 \mathrm{~B}$, No. 2, MAY 1948 
been used in toto as shown, and also as two separate anterior and posterior splints in cases of laminectomy of the cervical spine. A negative plaster-of-Paris cast is taken, bi-valved, and flanged in the usual way. The two separate halves are used as negative moulds in the pressure-blowing apparatus to obtain corresponding plastic moulds which, after being cut out, form the completed splint. The two halves are held together by buckle-straps threaded through marginal slots. Owing to the depth of blowing necessary to form the forehead portion, the plastic is rather thinned out here and a flat reinforcing band is subsequently attached to strengthen it.

The cervical support (Fig. 14) is made from the anterior half of a negative plaster-of-Paris cast. After pressure blowing, the plastic replica is trimmed so as to leave a breast plate, chin support, and two shoulder straps. An aperture is cut to allow free movement of the thyroid cartilage during deglutition. To permit comfortable rotation of the head, the edges of the chin support are everted or bevelled. This cervical support remains in position without any additional fixation straps and is designed only to prevent flexion of the cervical spine. 4. Hip spica (Fig. 15)-This splint is also made from a bi-valved and flanged negative plaster-of-Paris cast, using the pressure-blowing apparatus. The two halves of the completed plastic splint are held together by buckle-straps threaded through marginal slots.

5. Bucket and pylon (temporary walking prosthesis) (Fig. 16)-Because of the disadvantages of a temporary plaster-of-Paris bucket and pylon, the possibilities of producing a more efficient temporary limb at a reasonably low cost, and without undue delay, were investigated. The disadvantages of a temporary above-knee plaster-of-Paris prosthesis are: a) the form of the plaster bucket is such that the weight of the patient is not often taken on

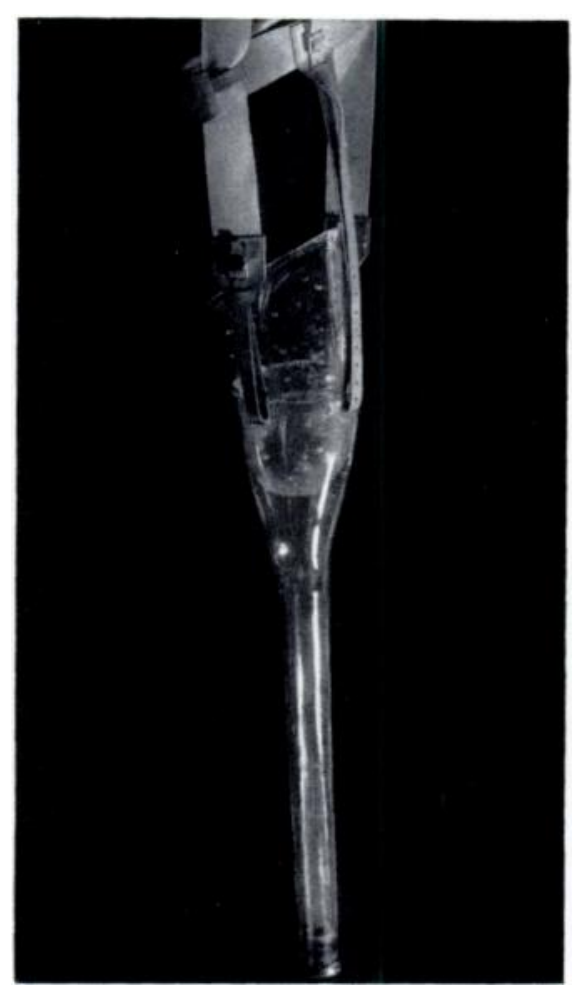

FIG. 16

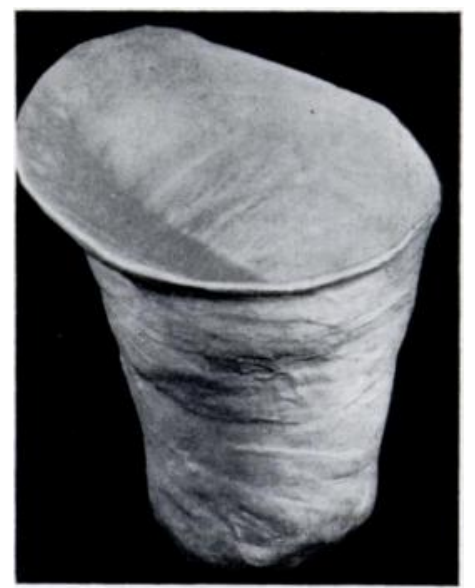

FIG. 17

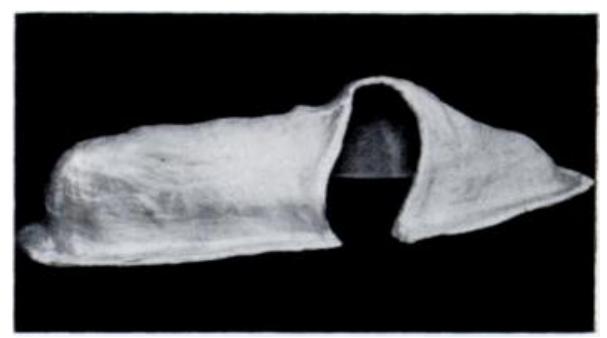

FIG. 18

Bucket and pylon (Fig. 16). Note the simple slot and strap attachment and rubber heel. Fig. 17 shows a plaster cast of an above-knee stump with everted brim for ischial-bearing. Fig. 18 shows the two halves of the divided plaster cast being bridged and flanged; the negative has been left open on one side to show how the two halves are joined. 


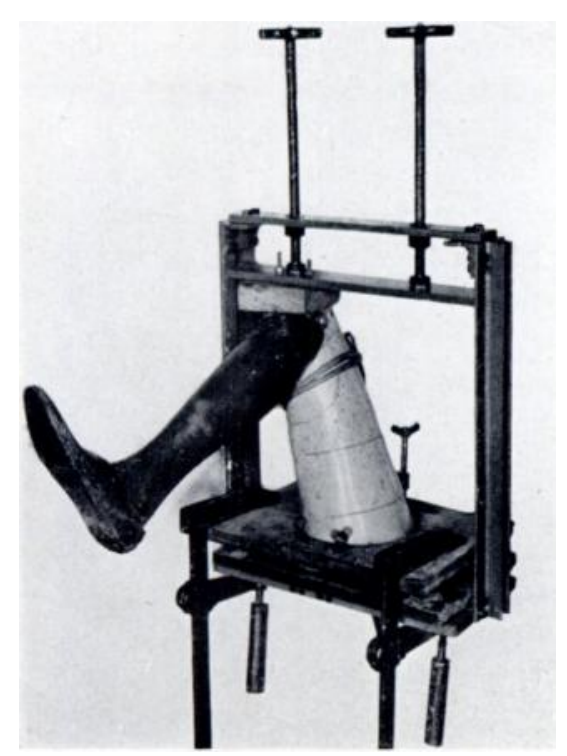

Fis. 19

Simple apparatus for making plastic liner--the limb is held tightly clamped.

the ischial tuberosity as in a permanent artificial limb, but around the circumference of the stump itself ; this causes a "step" or "roll" in the natural taper of the stump, and traction on the scar; b) for safe weight-bearing the plaster-of-Paris bucket has to be made thick, and when the pylon is attached the whole prosthesis is far too heavy; c) the stump sometimes becomes irritated by poor ventilation of the bucket.

Method of production of a plastic bucketI) Taking the cast-The first step is to attach with adhesive tape a length of medium bore pressure rubber tubing obliquely round the upper part of the thigh at the level of the ischial tuberosity postero-medially, and the base of the greater trochanter laterally. This ensures a properly shaped everted brim and ischial-bearing point in the finished plastic bucket. A length of stockinette is then applied over the stump, and plaster-of-Paris bandages used to make the cast. When set the cast is removed, the stockinette drawn out and the cast reapplied to make sure that it is an accurate fit, that it allows full flexion of the thigh, and that it does not press into the perineum (Fig. 17). 2) Preparing the plaster-of-Paris mould-When dry the negative cast is carefully divided longitudinally into equal halves (a surface gauge is a great help). These are placed on a flat surface, cut margins downwards, and wide ends facing each other about two to three inches apart. Then by the addition of plaster-of-Paris slabs bridging the gap and projecting all round, a continuous negative mould with flanges is obtained. (See Fig. 18-The cast has been left open one side to show the build-up.) 3) Making the plastic mould-When dry, the negative plaster-of-Paris cast is placed in the pressure-blowing apparatus. A three-sixteenth inch sheet of methyl methacrylate of appropriate size is heat-softened, clamped in the apparatus, and blown into the cast. When cool the plastic form is marked out in situ, then removed and carefully cut to yield the two halves. When cemented together with plastic dough these form an exact replica of the original negative plaster cast. The whole process can be completed in forty-eight to seventy-two hours, most of the time being needed for drying of the plaster-of-Paris cast and polymerisation of the plastic dough used

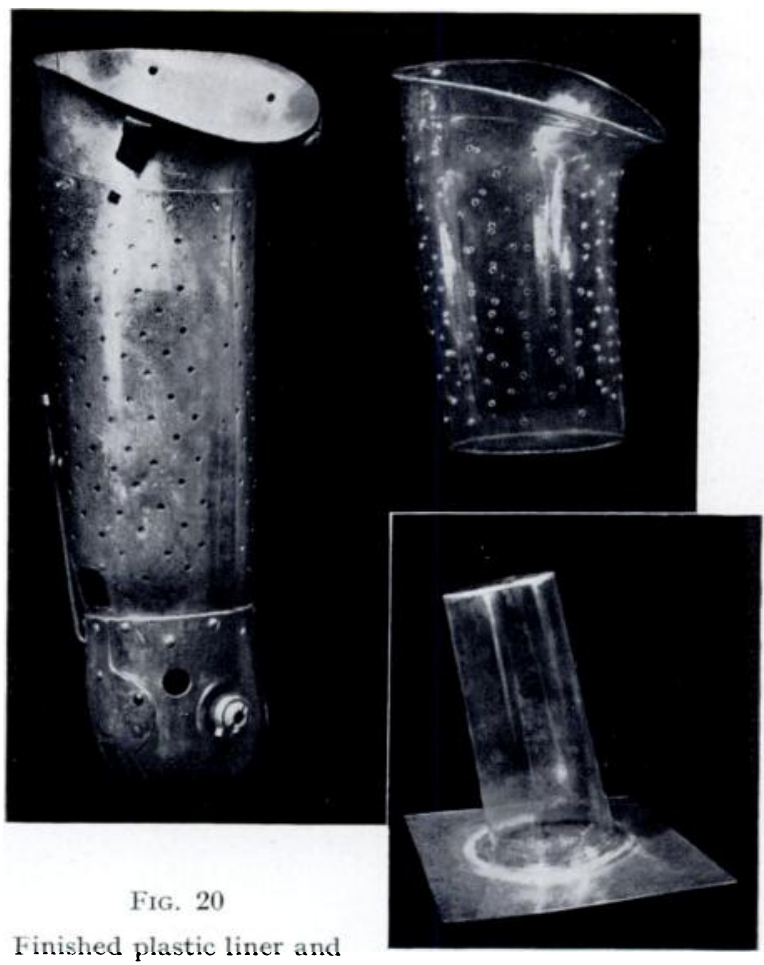

Finished plastic liner and standard " shape" used for making plastic liners. 
in joining the two halves together. Ventilation is ensured by drilling the material with one-eighth inch holes after the cementing operation. Fixation: The bucket is secured with plastic dough to a plastic pylon, preformed round a mandrel, and the suspension strap passed through slots cut in the cup of the pylon. The prosthesis shown in Fig. 16 has been worn successfully by a patient before the fitting of a permanent artificial limb. It was made entirely of methyl methacrylate, its total weight being $3 \frac{1}{2} \mathrm{lb}$. It is suggested that this method of bucket construction could be used in conjunction with a cheap, standard, jointed, and adjustable, artificial limb before the permanent limb is supplied to the patient. This temporary apparatus could be used for more than one patient by the simple process of changing the bucket. In this way the stiff-legged swinging gait which may develop with a straight-knee walking apparatus can be avoided.

6. Plastic liner-When a permanent artificial limb is supplied to a patient it is an advantage to be able to take up the steady shrinkage of the stump which often occurs over prolonged periods. For this purpose a plastic liner was evolved which is an exact fit in the above-knee metal bucket of the limb. It is capable of withdrawal and replacement by another liner of different thickness if required and is individually produced to fit each metal limb without any damage to it. Method of production-Standard "shapes" of methyl methacrylate have been constructed in four or five sizes (Fig. 20 inset). In appearance they are rather like a Welsh hat with crown set at an angle to the brim. A "shape" is heat-softened and placed inside the previously warmed bucket of the fully assembled limb. With the knee flexed at 90 degrees the upper part of the limb is held in the apparatus shown in Fig. 19. By clamping the flange of the "shape" between the two base-plates and releasing compressed air into it, the whole shape takes up the exact form of the inside of the bucket. Pressure is maintained until the material has cooled. The shape is removed and trimmed of excess material (Fig. 20). It has been found advantageous to grease the inside of the metal bucket to allow the plastic material to slide easily in it, and so prevent damage to its cellulose finish. Ventilation holes are easily drilled in the liner to correspond with those in the bucket. The time taken to produce such liners is approximately two hours. The apparatus required is not costly or elaborate. The patient is able to continue wearing his artificial limb to which he has become accustomed.

\section{CONGLUSIONS}

The advantages of plastics are well known, but there are still some who maintain that these materials are costly and difficult to manipulate. It is not usually remembered, however, that plastics already have their place in orthopaedic splint manufacture, for example in celluloid appliances of many kinds which are in everyday use. They are much lighter than plaster of Paris; they are unaffected by water and body secretions; and some are radiolucent. With the rapid development of modern plastics now taking place there is a wide field for research into their application in orthopaedic surgery. In describing a range of plastic splints and appliances, and outlining the details of their construction, we have tried to show that such research is worth while.

We wish to thank the Royal National Orthopaedic Hospital for facilities given us in carrying out this work, and the Resident Surgeon, Mr J. A. Cholmeley, F.R.C.S., for his interest and help.

We acknowledge our indebtedness, for supply of materials and valuable technical advice, to: Imperial Chemical Industries; B.X. Plastics, Ltd.; 'Triplex Safety Glass, Ltd.; Dufay Chromex L.td.; Bakelite, Ltd.; Fibreglass, Ltd.; A Boake Roberts \& Co., Ltd. We are grateful to Mr T. Fisher, our technical assistant, for his enthusiastic work, and to Mr R. J. Whitley, A.R.P.S., for the photographs. 